\title{
No needs to go to a gym: practicing qigong and yoga in small spaces at home - a personal reflection
}

\begin{abstract}
Many people spend a lot of money each month for gym and health club memberships. Purchase of these memberships goes up after Christmas and New Year as individuals make resolutions to get in shape and lose weight. Unfortunately, most do not carry through with these resolutions.

It is possible to pursue a personal routine in your own home using Qigong and Yoga Moreover, modern research has described health benefits from participating in these exercises not only for persons with medical conditions but also in helping to prevent illness, reduce stress, anxiety and depression, manage pain as well as helping to sustain an active lifestyle and increase longevity in relatively healthy individuals. Most significantly both forms of exercise can be performed without paying out tons of money on expensive membership fees!

No need to go to a gym is a personal reflection on 50years of practising Yoga and Qigong at home in small spaces. It is based on data collected from extensive research personal praxis during these 50 years. It provides clear directions on how to begin an Eastern based movement exercise program at home and some of the values of such practice to personal health.
\end{abstract}

Keywords: qigong, yoga, TCM, ayurveda, health, self care
Volume 12 Issue 4 - 2019

\author{
Bernie Warren \\ Drama in Education and Community, University of Windsor, \\ Canada
}

Correspondence: Bernie Warren, Drama in Education and Community, University of Windsor/Owner, Bear Moves Mountains 22 Mill StW. Leamington ON Canada, Emailmerv123@uwindsor.ca

Received: May 09, 2019 | Published: August 21, 2019

\section{Introduction}

The road to hell is paved with good intentions. ${ }^{1}$ Many people spend a lot of money each month for gym and health club memberships. Purchase of these memberships goes up after Christmas and New Year as individuals make resolutions to get in shape and lose weight. Unfortunately, many do not carry through with their resolutions. ${ }^{2}$

The reality is gyms, athletic clubs and fitness studios with their wide range of programs and personal trainers, provide many options and opportunities for health and fitness. However, it is not always necessary to walk, cycle or drive down to the gym to get healthy.

It is possible to pursue a personal routine in your own home using Qigong ${ }^{3,4}$ and Yoga,${ }^{5,6,7}$ based exercises each of which have documented history as health practices dating back more than 3,000yrs. Moreover, modern research has described health benefits from participating in Qigong and Yoga not only for persons with medical conditions (e.g. cancer; cardiac and respiratory problems; high blood pressure, diabetes, arthritis, and even spinal cord injuries ${ }^{8}$ ) but also in helping to prevent illness, reduce stress, anxiety and depression, manage pain as well as helping to sustain an active lifestyle and increase longevity in relatively healthy individuals. ${ }^{9,10,11}$

\section{No time (or space) to practice? - No excuses!}

Excuses are plentiful and cheap. We have all found reasons why we cannot do something. However, the beauty of Qigong and Yoga exercises is that they can be done almost anywhere and at any time and at no cost. It is possible to do most Qigong and Yoga exercises in very limited space. Most significantly both forms of exercise can be performed without paying out tons of money on expensive membership fees!
Qigong can be done seated, standing or moving and provides a thorough, non-stressful and extremely low impact work out for the whole body. It requires no special or expensive equipment. Yoga can be done using a mat, a wall kitchen counter or sink.

Every day I use different sets and combinations of these Qigong and Yoga exercises at home in my small apartment in 2-3day rotations. This allows me to cross train my body, working different sets of muscles and strengthening different physiological and immunological facets of my body.

What follows provides simple suggestions on how to begin a home-based exercise program and some of the value of such practice to personal health. ${ }^{12}$

\section{Preparing your home for practice}

An ideal space is one that is quiet, open with good light, with a view of trees and/or water. However, if this is not available find the most tranquil space and view available to you.

Preparing the room - Try to create a quiet clean area, one that provides:

a. Minimal distractions

i. If you live in a city apartment on a busy road try to find the quietest space possible

b. Move back all furniture to create as large an open space as possible

c. Even on the coldest winter day it is important to open a window(s) to let in fresh air 
d. Sweep, vacuum, mop the floor regularly

e. If using Counters or Sinks for stability - clean and dry the surfaces

f. If there is a fan in the room turn it on low

g. Close heating vents and/or turn down the thermostat

As electricity can affect the flow of Chi, ${ }^{13}$ try to practice away from electrical cables and overhead power lines. Even being too close to a wall carrying electrical wires may disrupt the flow of Chi.

\section{Preparing your body}

Many ancient texts have very specific directions about preparing the body for practice. These can include such things as cleansing the mind and the nine openings of the body..$^{14}$ However, for most of us trying to find time to do this, before we engage in exercise to help us cope with daily life, is likely to increase rather than reduce our stress!

That being said simply rushing from a stress filled work or home and expecting to instantly benefit from the exercises presented is a tall order. So, before you begin simply take three long, slow breaths, ${ }^{15}$ while letting go of your thoughts and troubles on each out-breath.

What should I wear? It is possible to practice in any outfit (or even naked) however it is probably best to wear loose comfortable clothes e.g.

a. T-shirt and/or sweat shirt

b. Yoga, 'harem' or track pants

c. I would also recommend wearing:

i. Layers, so that you may add or remove clothing as needed.

ii. Breathable and natural fabrics if at all possible.

It is best to remove as much jewellery as possible as this can affect the flow of energy. These include your watch, and bracelets and earrings as well as any other body piercing rings. ${ }^{16}$

When practising indoors at home, working barefoot or in light cotton socks work well. If you feel the need to wear footwear, then wear a light shoe like water shoes or canvas deck shoes or Martial Arts slippers. Try to avoid heavy runners or cross trainers as they often restrict energy flow through the ankle.

When should I practice? While Ancient texts often have very specific directions about when to practice, what direction to face and what exercise should be done, at what time to gain maximum benefit, I usually suggest that there are four times of day that are particularly good: Sunrise, Midday, Sunset, Midnight. However, after that I usually recommend choosing any time you are able to find that will work for you consistently!

How often and for how long should I practice? ${ }^{17}$ My suggestion is always to start slowly and build up. At the beginning if you are able to build these exercises into your routine 2-3times a week that is a good start.

Many people like to create a routine, a time they set aside to practice these exercises. Others fit in the exercises wherever and whenever they can. Finding even 5-10minutes at any time during the day can produce positive effects.

\section{Should I play music while practising?}

I am often asked about whether to use music. This is I feel, very much a personal choice. Like many other people, I often play soft relaxing music ${ }^{18}$ while I practice (even when I am outside), especially when teaching classes. However, I know many teachers and practitioners who prefer silence or natural sounds when outside.

\section{Some suggested home-based yoga and qigong exercises}

The following suggested exercises and sequences require very little time or space - all you need is enough space to raise each arm out in an arc from your sides to above your head. Or a space to place a mat or blanket on a floor.

\section{Floor ${ }^{19}$ and wall ${ }^{20}$ based adapted yoga}

Several years ago, I injured my hip. The issue was in part age related but mainly it was aggravated from sitting and driving $50 \mathrm{kms}$ each way to work every day. These injuries have been aggravated by a genetic predisposition to knee problems that runs in my family and the weight I have gained since I turned 50.

I also had (and still have periodically) problems with both knees, ${ }^{21}$ (injuries sustained from playing full contact sports when I thought I was immortal) and extremely tight IT bands which exacerbated these problems. Over the years I tried chiropractic and massage (at the time I had a wonderful chiropractor and a marvellous massage therapist) and these treatments did help for a while, but the problem always returned. I decided to see a physiotherapist. At the time she was hosting my Qigong classes at her clinic and so was also one of my Qigong students. While we always had heated discussions about East and West approaches to "healing", we respected and learned from one another and from time to time simply agreed to disagree!

I first saw her for about 6 weeks. ${ }^{22}$ After each session she always sent me home with a set of exercises which I often adapted based on my own knowledge. Anyway, many of my homework tasks were adapted Yoga exercises..$^{23}$ These helped reconnect me to the Yoga I had studied several years before.

Since that first visit, I have included Therapeutic Yoga exercises into my weekly routines and I now try to practice these 3-4 times a week. As a result, my full morning practice now takes at least $70 \mathrm{mins}$. It includes rotating Qigong/Martial Arts $\operatorname{Sets}^{24}$ (45-55mins) and floor wall and counter stretches (25-35mins). All the sets I practice include mindfulness and Meditation. Some days, I do not feel like doing a full set and on these days, I do a shorter session - but I make sure I do some floor-based exercises each week.

So, I watch what I eat and try to keep my weight within a manageable target range for health reasons NOT because of vanity but because I have found that even 5 extra $1 \mathrm{bs}(2.2 \mathrm{Kgs})$ aggravates my problems. While an extra $10 \mathrm{lbs}(4.5 \mathrm{Kg})$ creates the possibility of being confined to bed. I should add 2 caveats I am not always successful in this goal and I, like most people, do care what I look like.

\section{Standing at the kitchen counter 25,26}

I have taught dance-movement classes for over 40years to students and professional artists of all ages and abilities. In 1984 I came across the marvellous book Teaching Dance to Senior Adults by the wonderful Liz Lerman. What I read and saw of her work was 
an inspiration. One thing that stuck in my mind was her use of chairs, instead of the traditional stationary handrail, for Barre Work - ballet and dance training and warm up exercises. Now 30years later I find myself using my Kitchen counter for Barre work and some Yoga Exercises period.

\section{Zhan zhuan - standing like a tree ${ }^{27}$ a free-standing exercise that requires (almost) no time or space}

Many of the more sedentary exercises e.g. Standing Like a Tree, are subtle enough that they can be performed while waiting for a bus or while standing in line (at the bank, a grocery store etc.), or at home. ${ }^{28}$

In strict traditional martial arts practice novice students are often required to hold individual postures for long periods of time and must 'master' the architecture of the pose before learning the next. This standing practice is an essential part of the traditional martial arts practice and has many benefits.

For the martial artist it helps the body remember the exact position of a block or a strike so that, similar to driving a car, when a move is needed it is instinctual. More than this, when holding a posture without effort blood and energy flow more freely helping to strengthen the body and to bring all bodily functions into balance.

The Qigong and Yoga practice, such as the few simple exercises suggested above, require little or no preparation and can be performed almost anywhere, at any time, for as long or as short as you like.

Like most exercise programs, the effects of the exercises are cumulative. Initially it is better to do a 5-minute burst 10 times during the day than 40minutes all at once. As your body becomes more accustomed to these exercises you can extend the time you allocate to your practice!

My own experience, and those of my students, ${ }^{29}$ is that within 4-6weeks of introducing even 5-10minutes of Yoga or Qigong exercises into your routine 2 to 3 times a week you will start to see health benefits - more energy and less illness. ${ }^{30}$ All you have to do is start.

\footnotetext{
${ }^{1}$ The saying is often attributed to Saint Bernard of Clairvaux, although others suggest its origin is much earlier being a paraphrase of a quote in Virgil's Aeneid.
}

${ }^{2}$ Recent research $(2018 \mathrm{n}=4,000)$ found that $95 \%$ of New Year's Resolutions are fitness related, it also found that $43 \%$ of people give up their goal after just one month and after just 3 months, only $10 \%$ of people stuck with their fitness resolution.

${ }^{3}$ Qigong (usually translated as Breath Power or Energy Work), the Chinese practice of aligning breath, movement, and awareness for exercise, healing, and martial arts training, extends back more than 4,000years.

${ }^{4}$ According to the traditional Chinese medical community, the origin of qigong is commonly attributed to the legendary Yellow Emperor (2696-2598 BCE) and the classic Huangdi Neijing book of internal medicine.

${ }^{5}$ The beginnings of Yoga were developed by the Indus-Sarasvati civilization in Northern India around 2700 BCE.

${ }^{6}$ Yoga is more than the physical asanas associated with modern yoga classes. The true meaning of yoga is union with the Divine. The assana or bodily stretching is a relatively new phenomenon that has arisen in the last century. In pre-modern India, the āsana was always one auxiliary among many, of a complete psycho-physiological system of disciplined yoga practice, enjoined alongside other yoga directives including: ethical restraints and observances (yama and niyama), breath control (prānāyāma) and retention (kumbhaka), bodily seals (mudrā) and binds (bandha), and meditation techniques (dhyāna), among others.

${ }^{7}$ https://www.healthline.com/nutrition/13-benefits-of-yoga

${ }^{8}$ Even more profound is the use of Qigong in combination with modern Western Medical approaches.

${ }^{9} \mathrm{https} / / /$ www.ncbi.nlm.nih.gov/pmc/articles/PMC3085832/

${ }^{10} \mathrm{https}: / / \mathrm{www}$.energyarts.com/qigong-benefits/

${ }^{11}$ I am a living testament to the value of these exercises which I have been practicing for over 50years. (FYI: at the time of writing this article I am, according to my doctors, an extremely healthy 65 years old).

${ }^{12}$ Much of what follows is adapted from, Warren B, Coughlin J. Stand breathe smile: simple standing exercises and approaches to reduce stress and promote good health. Oxford, UK: tranquility press.

${ }^{13}$ best thought of as: bio-electrical energy

${ }^{14}$ When the ancient texts were first written the exercises were probably only meant to be learned by men. The nine openings (the two eyes, two ears, two nostrils, one mouth \& two lower openings) are accurate for men but for women this would need to be amended ten.

${ }^{15} \mathrm{My}$ teacher Master Hu once made a comment that meditation is simple, you breathe in and out slowly and smoothly three times while clearing your mind.

${ }^{16}$ Some masters argue that ALL jewellery and body piercings should be removed during practice as these disrupt the flow of $\mathrm{Chi}$

${ }^{17}$ As my senior student John Taylor reminded me, I used to reply. "How long do you have?"

${ }^{18}$ In the last several years the availability of New Age music has led to a wide range of possibilities of music to choose from. Currently I use:

a. Deuter: Wind and Mountain - particularly the tracks:

i. Wind and Mountain

ii. Island in the Sun

b. However, over the years I have also used various other pieces of music e.g.

i. Pachelbel's Canon in D with Ocean Waves

ii. Anzan Reflections of Nature: Zen \& The Art of Relaxation

${ }^{19}$ For more information on basic Yoga exercises to start with I recommend the following:

http://www.yogabasics.com/

Ann Dawson Insight Yoga: An Innovative Synthesis of Traditional Yoga, Meditation, and Eastern Approaches to Healing and WellBeing https://www.amazon.ca/Insight-Yoga-Innovative-TraditionalMeditation/dp/1590305981/ref=sr_1_1?hvadid=208348618282\&hvde $\mathrm{v}=\mathrm{c} \& \mathrm{hvloc}$ hy $=9001092 \& \mathrm{hvnet}_{\mathrm{w}}=\mathrm{g} \& \mathrm{hvpos}=1 \mathrm{t} 1 \& \mathrm{hvqmt}=\mathrm{e} \& \mathrm{hv}$ rand $=12124322007442113051 \&$ hvtargid $=$ kwd- $298735698187 \&$ keywords $=$ insight + yoga $\&$ qid $=1553786022 \& \mathrm{~s}=$ gateway $\& s r=8-1$

${ }^{20}$ Legs up the wall pose (viparita karani)

1. Lay flat on your back on a yoga mat or a blanket near a wall or solid door

2. Shimmy your hips as close to the wall as possible,

3. Start walking your feet up the wall

i. Place the back of your legs against the wall, so that the soles of your feet face upwards. 
ii. It will take you a little bit of movement to get comfortable in this position.

4. Make sure your back and head are resting on the floor.

i. So that your body forms a 90-degree angle.

5. Make any adjustments to make this comfortable

6. E.g. if needed place a thin pillow under your head, or

7. Let your arms rest on your belly or out to the sides.

8. Close your eyes and breathe.

9. Hold this position for at least eight full slow breaths

10. When ready bring your knees towards your chest slowly and roll to any one side.

11. Breathe before you sit up.

12. Benefits:
a. Alleviates headaches
a. Boosts energy
b. Soothes menstrual cramps
c. some yoga traditions advice against doing this during menstruation
d. Relieves lower-back pain

13. Precautions:
a. Glaucoma
b. Hypertension
c. Hernia

14. Happy baby wall pose (variation on ananda balasana)

a. Lay flat on your back on a yoga mat or a blanket near a wall or solid door

b. Place your hips as close to the wall as possible

c. Place the soles of your feet on the wall about hip width apart

d. Have the feet comfortably apart, which for you may be approximately hip width apart

1. Allow your sacrum to sink so that it is flat on the floor.

e. Let your arms rest on your belly or out to the sides.

f. Close your eyes and breathe.

g. Hold this position for at least eight full slow breaths

h. When ready bring your knees towards your chest slowly and roll to any one side.

i. Breathe before you sit up.

15. Benefits:

a. Compresses the stomach $\rightarrow$ massaging the organs in the digestive system.

b. Helps reduce the heart rate $\rightarrow$ relaxing and calming the mind.

16. Precautions

a. to avoid injury, ensure your spine is absolutely straight.

b. If you have knee injuries be especially careful to keep them in alignment with your first toe. c. Do not practice during the late stages of pregnancy.

People suffering from high blood pressure should not hold your breath.

${ }^{21}$ I should add that I severely injured my spine from a fall in 1982 and have neck and knee from injuries sustained through my pursuit of full contact sports.

${ }^{22}$ Over next 10years I visited periodically when I experienced other minor structurally issues with my body.

${ }^{23}$ These exercises were drawn from several books:

Egoscue P, Gittines R. Pain Free: A Revolutionary Method for stopping Chronic Pain. USA: Random House; 2000. p. 320.

Powers S. Insight Yoga: An Innovative Synthesis of Traditional Yoga, Meditation, and Eastern Approaches to Healing and Well-Being. Boston, UK: Shambala Publications; 2008.

${ }^{24} \mathrm{~A}$ set is a series of exercises done in a particular sequence e.g. the Ba Duan Jin. A set may also include several sets of exercises also done in a particular sequence.

${ }^{25}$ These exercises can also be performed on the balcony of a ship or an apartment (flat). Simply use the railing instead of a kitchen counter.

${ }^{26}$ Half plank pose (phalakasana)

This is not a true PLANK pose, hence the "Half' in the title.

1. Stand approximately 3.5-4-foot lengths from your kitchen counter

2. Your feet should be

3. One-foot width apart

4. Outside edges parallel to one another

5. Breathe in

6. raise your hands above your head

7. Breath out

8. Bend from the waist until your palms are flat on the kitchen counter

9. Your back should now be at 90 to your hips and Parallel to the floor

10. Keep your spine straight,

11. Do not raise or lower your Chin as this puts a strain on your neck

12. Keep your arms shoulder width apart with your palms flat apart on the counter

13. Breathe in and out normally EIGHT (8) time

2.

14. Cobra pose (bhujangasana)

15. Stand in Half Plank Pose 3.5-4-foot lengths from your kitchen counter

16. Keep your arms shoulder width apart with your palms flat apart on the counter

17. Relax your elbows

18. Breathe in

19. Release your Knees

20. Arch your spine and head fully

21. Do not strain or force this movement

22. Relax your hips, belly and chest so that they move passively towards the floor 
23. Breathe Out

24. Relax and Breathe in and out 8 EIGHT times

25. Barre work - is it ballet or is it martial arts?

a. This exercise is my take on a combination of a simple Ballet Barre exercise, Kung Fu/Qigong - Flying Crane and Yoga (Virahandrasana III / Warrior Pose III)

b. Standing in "Half" Plank Pose 3.5 - 4foot lengths from your kitchen counter

c. Bring your feet together

d. Keep your arms shoulder width apart with your palms flat apart on the counter

e. Breathe In

f. Raise your Right Knee until your leg is parallel to the floor

g. Your Toes point towards the floor

h. B) Breathe out

i. Extend your leg backwards until you reach full extension

j. This creates a straight line from the tip of your toes to the tips of your fingers

k. Breathe In

I. Bring your knee towards your chest until your leg is parallel to the floor

m. Your Toes point towards the floor (Position A above)

n. Breathe Out

o. Drive your heel towards the floor at a $45^{\circ} \mathrm{C}$ angle until your leg is straight

p. Do NOT lock your Knee

q. Breathe In

r. Draw your knee back towards your body

s. Until you are once again in Position A above

t. Breathe Out

u. Place your foot back on the floor until you are back at starting position

Repeat this sequence EIGHT times -alternating Right and Left Legs i.e. 4 times on each side.

The quality of your breathing used in this exercise changes its intent.

i. Short In breaths with a pronounced exhale "ha" = Practice of Martial Arts Kicks

ii. Long Slow Breaths to the full extent of the movement = Practice for Dance/Ballet Barre

Holding each position for a long slow In and Out Breath = Qigong/Yoga practice

${ }^{27}$ Standing like a tree

\section{A. Stand with your}

a. Legs hip width apart - approximately one-foot width between the arches of your two feet b. Feet flat on the floor,

c. Parallel to one another

d. Knees bent, but not extended beyond your toes

e. Shoulders relaxed and,

f. Spine straight but not rigid

g. Your eyes look at a point in the distance that is parallel to the ground

B. Move your hips slightly backwards, as if sitting down on a high bar stool or on a horse

a. So that your shoulders are slightly forward of your hips.

b. Point your elbows away from your body with your palms facing towards your thighs

c. Do NOT tighten your stomach muscles, rather keep the front of your body soft

d. Close your mouth, so that your teeth touch and your tongue lightly touches the roof of your mouth.

e. Inhale and out naturally without holding or forcing your breath

\section{Precautions}

a. Make sure your knees are released but not so much that they extend over the end of your toes

b. Benefits:

Wu Chi is a simple but potent weapon in the fight against stress and stress related diseases Research suggests standing for 5 minutes in this position has the same cardio-vascular effect as walking for 20 minutes on a treadmill at a moderate pace.

${ }^{28}$ For more exercises like Standing Like A Tree, See:

Lam M, Chuen K. The Way of Energy: mastering the Chinese art of internal strength with Chi Kung exercise. New York: Simon and Schuster/ Fireside; 1991. p. 192.

Warren B, Coughlin J. Stand Breathe Smile: Simple standing exercises and approaches to reduce stress and promote good health. Oxford, UK: Tranquility Press; 2014.

${ }^{29}$ Warren B, Mason R, Saed B. Seeking the dragon's pearl: reflections on the benefits of taijiquan \& qigong for university students. Int J Complement Alt Med. 2018;11(2):57-60.

${ }^{30} \mathrm{As}$ my teachers say, it is not that you will not get sick but you will be sick less often and the bouts of illness you do experience will be less severe and for shorter periods.

\section{Acknowledgments}

I wish to thank all my teachers, particularly Master George Ling $\mathrm{Hu}$, for introducing me to the health benefits of Qigong and Yoga

\section{Conflicts of interest}

The authors declare that there are no conflicts of interest.

\section{Funding}

None. 